\title{
STRATEGI NASIONAL UNTUK PENDIDIKAN DAN PELATIHAN DI BIDANG PROTEKSI DAN KESELAMATAN RADIASI
}

\author{
Eri Hiswara ${ }^{1}$ \\ 1) Pusat Teknologi Keselamatan dan Metrologi Radiasi, Badan Tenaga Nuklir \\ Nasional, Jalan Lebak Bulus Raya No. 49, Jakarta Selatan \\ Email: e.hiswara@batan.go.id
}

\begin{abstract}
ABSTRAK
STRATEGI NASIONAL UNTUK PENDIDIKAN DAN PELATIHAN DI BIDANG PROTEKSI DAN KESELAMATAN RADIASI. Aplikasi tenaga nuklir untuk tujuan peningkatan taraf hidup dan kesejahteraan masyarakat telah berkembang dengan pesat di Indonesia. Mengingat tenaga nuklir juga memberikan risiko kesehatan yang cukup tinggi, setiap aplikasi tersebut perlu dikelola dengan baik dan hatihati. Salah satu upaya untuk mengelola kegiatan pemanfaatan radiasi agar tidak menimbulkan risiko atau bahaya adalah dengan melakukan tindakan proteksi dan keselamatan radiasi di setiap kegiatan pemanfaatan tersebut. Untuk itu setiap instalasi atau fasilitas yang menggunakan tenaga nuklir harus memiliki sumber daya manusia yang trampil dan ahli dalam bidang proteksi dan keselamatan radiasi. Makalah ini membahas tentang strategi nasional untuk pendidikan dan pelatihan (diklat) di bidang proteksi dan keselamatan radiasi yang perlu disusun agar ketersediaan tenaga proteksi dan keselamatan radiasi tersebut dapat tersedia sesuai kebutuhan. Pembahasan meliputi analisis kebutuhan diklat, rancangan program diklat nasional, pengembangan dan penerapan program diklat, dan evaluasi program diklat. Penyusunan strategi nasional dapat diawali oleh institusi nasional yang memiliki tugas di bidang ketenaganukliran seperti Badan Tenaga Nuklir Nasional (BATAN) atau Badan Pengawas Tenaga Nuklir (BAPETEN), namun juga dapat dilakukan oleh institusi universitas atau perguruan tinggi yang memiliki kepedulian terhadap pengembangan sektor ketenaganukliran secara umum dan bidang proteksi dan keselamatan radiasi secara khusus di Indonesia.
\end{abstract}

Kata kunci: Strategi nasional, pendidikan dan pelatihan, proteksi dan keselamatan radiasi

\section{ABSTRACT}

NATIONAL STRATEGY FOR EDUCATION AND TRAINING IN THE FIELD OF RADIATION PROTECTION AND SAFETY. The application of nuclear energy for the purposes of improving people's standard of living and welfare have developed rapidly in Indonesia. Given that nuclear energy also provides a high enough health risk, each of these applications needs to be managed properly and carefully. One effort to manage radiation utilization activities so as not to pose a risk or danger is to carry out radiation protection and safety measures in each of these utilization activities. For this reason, each installation or facility that uses nuclear energy must have skilled human resources and experts in the field of radiation protection and safety. This paper discusses national strategies for education and training in the field of radiation protection and safety that need to be prepared so that the availability of protection and radiation safety can be available as needed. The discussion includes training needs analysis, the design of national education and training programs, development and implementation of training programs, and education and training program evaluations. The preparation of national strategies can be initiated by national institutions that have tasks in the nuclear sector such as the National Nuclear Energy Agency (BATAN) or the Nuclear Energy Regulatory Agency (BAPETEN), but can also be carried out by university or higher education institution that have concern for the development of the nuclear sector in general and the field of radiation protection and safety in particular in Indonesia.

Key words: national strategy, education and training, radiation protection and safety 


\section{PENDAHULUAN}

Aplikasi tenaga nuklir di berbagai bidang seperti medik, industri, pertanian dan penelitian yang ditujukan untuk meningkatkan taraf hidup dan kesejahteraan masyarakat telah berkembang dengan pesat di Indonesia. Berdasar data Badan Pengawas Tenaga Nuklir (BAPETEN, sampai akhir Februari 2019 telah dikeluarkan sebanyak 11919 izin pemanfaatan tenaga nuklir untuk 3306 instansi [1]. Dari jumlah izin pemanfaatan terebut, sebanyak 5611 dan 6291 izin masing-masing dikeluarkan untuk sektor industri dan kesehatan, dengan jumlah instansi sebanyak 1015 dan 2291. Dengan demikian, lebih dari 50\% izin dan instansi pemegang izin bergerak di sektor kesehatan.

Disamping memberikan manfaat yang besar bagi kesejahteraan manusia, aplikasi radiasi di berbagai bidang juga diketahui memiliki risiko kesehatan yang tinggi bagi manusia jika aplikasi tersebut tidak dikelola dengan baik dan hati-hati. Salah satu upaya untuk mengelola kegiatan pemanfaatan tenaga nuklir agar tidak menimbulkan risiko atau bahaya adalah dengan melakukan tindakan proteksi dan keselamatan radiasi di setiap kegiatan pemanfaatan tersebut. Dengan demikian, setiap instalasi atau fasilitas yang menggunakan tenaga nuklir harus memiliki sumber daya manusia yang trampil dan ahli dalam bidang proteksi dan keselamatan radiasi.

Pada saat ini tidak ada strategi nasional untuk pendidikan dan pelatihan di bidang proteksi radiasi. Dengan demikian, makalah ini akan membahas strategi nasional dalam pendidikan dan pelatihan yang perlu disusun untuk memenuhi kebutuhan tenaga proteksi dan keselamatan radiasi di Indonesia. Pembahasan akan difokuskan dari sisi peraturan perundangan, penilaian kebutuhan, serta desain program pendidikan dan pelatihan yang diperlukan.

\section{TEORI}

\section{Proteksi dan keselamatan radiasi}

Peraturan Pemerintah (PP) Nomor 33 Tahun 2007 mendefinisikan proteksi radiasi sebagai 'tindakan yang dilakukan untuk mengurangi pengaruh radiasi yang merusak akibat paparan radiasi', dan keselamatan radiasi sebagai 'tindakan yang dilakukan untuk melindungi pekerja, anggota masyarakat, dan lingkungan hidup dari bahaya radiasi' [2]. Dengan demikian, tindakan proteksi dan keselamatan radiasi menjadi salah satu unsur yang sangat penting dalam memanfaatkan tenaga nuklir secara aman dan selamat.

\section{Peraturan perundangan}

Peraturan perundangan ketenaganukliran tertinggi di Indonesia adalah Undang-Undang No. 10 Tahun 1997 tentang Ketenaganukliran. UU No. 10 Tahun 1997 ini mengatur beberapa hal terkait dengan ketenaganukliran, yaitu kelembagaan, penelitian dan pengembangan, pengusahaan, pengawasan, pengelolaan limbah radioaktif, pertanggungjawaban ketenaganukliran, dan tiga ketentuan normatif mengenai pidana, peralihan dan penutup.

Terkait dengan proteksi dan keselamatan radiasi, Pasal 16 UU No. 10 Tahun 1997 menyatakan bahwa 'setiap kegiatan yang berkaitan dengan pemanfaatan tenaga nuklir wajib memperhatikan keselamatan, keamanan, dan ketenteraman, kesehatan pekerja dan anggota masyarakat, serta perlindungan terhadap lingkungan hidup.

Namun demikian, dalam UU No.10 Tahun 1997 ini sama sekali tidak ada ketentuan yang berkaitan dengan pengembangan sumber daya manusia (SDM) di bidang ketenaganukliran ini, termasuk SDM di bidang proteksi dan keselamatan radiasi. Berbagai peraturan pelaksanaan dari UU No. 10 Tahun 1997 ini juga tidak ada yang secara eksplisit menyatakan diperlukannya sumber daya manusia yang relevan untuk pengembangan iptek ketenaganukliran di Indonesia.

\section{Kondisi saat ini}

Secara formal saat ini tidak ada program pendidikan pada perguruan tinggi yang memiliki jurusan atau bahkan peminatan di bidang proteksi dan keselamatan radiasi. Hal ini berbeda jauh dengan kondisi tahun akhir tahun 1970an hingga awal tahun 1980an saat Badan Tenaga Atom Nasional (BATAN) saat itu bekerjasama dengan Jurusan Fisika FIPIA UI membuka peminatan Fisika Kesehatan dan Proteksi Radiasi dan Instrumentasi Nuklir yang berhasil meluluskan tidak kurang dari 200 sarjana strata satu [3]. 
Kebutuhan akan tenaga proteksi dan keselamatan radiasi di masyarakat saat ini dipenuhi oleh pelatihan Petugas Proteksi Radiasi (PPR) untuk tenaga yang akan bekerja baik di instansi pemerintah maupun swasta yang memanfaatkan sumber radiasi dan bahan radioaktif. Tabel 1 memberikan data beberapa instansi yang dengan penunjukan oleh BAPETEN telah menyelenggarakan pelatihan PPR.

Tabel 1. Penyelenggara pelatihan PPR.

\begin{tabular}{cll}
\hline No. & \multicolumn{1}{c}{ Instansi } & \multicolumn{1}{c}{ Jenis PPR } \\
\hline 1 & Pusdiklat BATAN & $\begin{array}{l}\text { PPR Medik Tingkat } \\
\text { (Tk.) 1, 2 dan 3, } \\
\text { PPR Industri Tk. 1, 2 } \\
\text { dan 3 }\end{array}$ \\
\hline 2 & STTN BATAN & PPR Industri Tk. 1 \\
\hline 3 & $\begin{array}{l}\text { Diklat Center, } \\
\text { Yogyakarta }\end{array}$ & PPR Medik Tk. 2 \\
\hline 4 & ATRO Bali & PPR Medik Tk. 2 \\
\hline 5 & Poltekkes Jakarta & PPR Medik Tk. 2 \\
\hline 6 & $\begin{array}{l}\text { BP Training Center } \\
\text { Undip }\end{array}$ & PPR Medik Tk. 2 \\
\hline 7 & Poltekkes Semarang & PPR Medik Tk. 2 \\
\hline 8 & $\begin{array}{l}\text { Prodi Radiologi FK } \\
\text { Unair }\end{array}$ & PPR Medik Tk. 2 \\
\hline
\end{tabular}

\section{Kebijakan dan Strategi Nasional Keselamatan Nuklir dan Radiasi Bidang Sumber Daya Manusia}

Untuk meningkatkan koordinasi antar instansi pemerintah dan sebagai arahan pendukung infrastruktur pengawasan ketenaganukliran, telah ditetapkan Peraturan Presiden (Perpres) tentang Kebijakan dan Strategi Nasional (Jakstranas) Keselamatan Nuklir dan Radiasi [4].

Secara umum, Jakstranas dijabarkan dalam sebelas bidang, salah satunya adalah bidang sumber daya manusia. Dua kebijakan di bidang sumber daya manusia dengan masingmasing strateginya adalah sebagai berikut:

a. Kebijakan: Pengembangan infrastruktur dalam rangka peningkatan keselamatan nuklir dan radiasi

Strategi:

- Peningkatan ketersediaan dan optimalisasi sarana dan prasarana untuk peningkatan keselamatan nuklir dan radiasi

- Pengembangan sistem informasi yang mendukung peningkatan keselamatan nuklir dan radiasi. b. Kebijakan: Peningkatan koordinasi antar sektor yang terkait dengan keselamatan nuklir dan radiasi

Strategi:

- Peningkatan efektivitas pengawasan keselamatan nuklir dan radiasi melalui peraturan, perizinan, dan inspeksi

- Penyinergian pelaksanaan tugas dan fungsi masing-masing sektor terkait untuk meningkatkan keselamatan nuklir dan radiasi.

\section{Rekomendasi IAEA}

Berdasar IAEA [5], tujuan umum dari pendidikan dan pelatihan (diklat) di bidang keselamatan radiasi, dan juga keselamatan pengangkutan dan limbah, adalah membangun dan memelihara tingkat kompetensi yang layak yang sesuai dengan rentang fasilitas dan kegiatan yang ada di suatu negara. Karena itu, kebutuhan diklat akan sangat ditentukan oleh:

- rentang fasilitas dan kegiatan, saat ini maupun yang akan datang

- kerangka hukum dan peraturan, terutama yang berkaitan dengan persyaratan pendidikan dan pelatihan yang relevan.

Pembangunan kompetensi diklat secara berkelanjutan dapat dibantu dengan menyusun strategi nasional yang didasarkan pada kebutuhan dengan mempertimbangkan sumber daya dan kapabilitas untuk diklat yang tersedia. Gambar 1 memberikan empat tahapan dalam menyiapkan strategi nasional untuk pembangunan kompetensi di bidang proteksi dan keselamatan radiasi [6].

Tahapan pertama adalah analisis kebutuhan diklat. Tujuan analisis adalah untuk mengidentifikasi dan memprioritaskan diklat yang dibutuhkan. Untuk melakukan analisis ini diperlukan tiga komponen, yaitu [5]:

a. pengumpulan informasi mengenai fasilitas dan kegiatan yang ada,

b. analisis persyaratan diklat yang ditentukan pada kerangka hukum dan peraturan, ditambah persyaratan khusus terkait dengan kualifikasi profesional; dan

c. evaluasi jumlah personil untuk setiap kategori profesional yang memerlukan diklat, termasuk pertimbangan mengenai kebutuhan akan pelatihan penyegaran. 


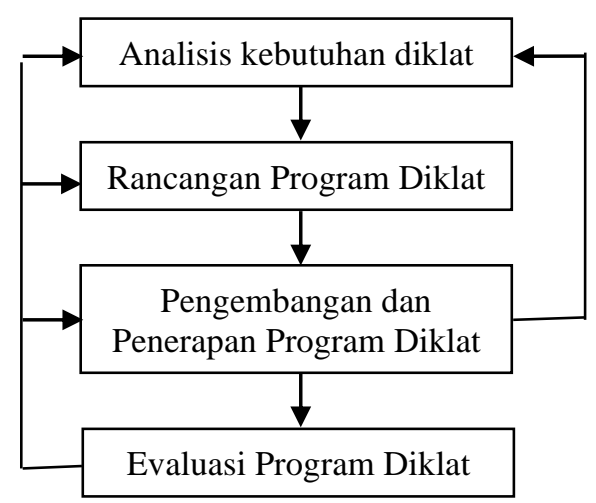

Gambar 1. Tahapan dalam menyiapkan strategi nasional untuk pendidikan dan pelatihan di bidang proteksi dan keselamatan radiasi.

Berdasar hasil analisis tahap pertama, fokus tahap kedua adalah merancang program diklat nasional yang akan memenuhi semua kebutuhan yang telah diidentifikasi. Beberapa parameter yang mempengaruhi perancangan program adalah [5]:

a. jumlah orang yang akan dilatih untuk fungsi pekerjaan yang relevan pada setiap fasilitas dan kegiatan;

b. jenis diklat yang diperlukan (mis. akademik pada strata satu atau dua, pelatihan dasar atau khusus, kompetensi ilmiah atau teknis);

c. kemampuan nasional yang ada (mis. sumber daya manusia, fasilitas, keadaan finansial);

d. konteks internasional (mis. sumber daya tersedia dan dapat diakses di luar negeri, dukungan dari organisasi internasional).

Setelah perancangan diklat nasional selesai dilakukan, tahap selanjutnya adalah mengembangkan dan menerapkan program yang telah disusun. Dalam hal ini yang perlu diperhatikan adalah diklat yang akan dilakukan harus cocok dengan metodologi yang akan diberikan, misalnya apakah dalam bentuk kursus, pelatihan di tempat kerja, atau pembelajaran jarak jauh [5]. Fasilitas pelatihan dan tenaga pengajar juga perlu disesuaikan dengan metode diklat yang akan dilakukan.

Setelah berjalan beberapa lama, program diklat perlu dievaluasi untuk memastikan bahwa pilihan jenis diklat yang diambil telah sesuai dengan kebutuhan, dan program secara keseluruhan telah sesuai dengan perkembangan iptek proteksi dan keselamatan radiasi. Metodologi penilaian diklat yang dilakukan
IAEA [7] dapat digunakan sebagai acuan untuk melakukan evaluasi terhadap program diklat di bidang proteksi dan keselamatan radiasi ini.

\section{METODE}

Pembahasan mengenai strategi nasional dalam pendidikan dan pelatihan di bidang proteksi dan keselamatan radiasi pada makalah ini dilakukan dengan acuan utama publikasi IAEA Safety Report Series No. 93 [5]. Kajian dilakukan secara deskriptif, analitik dan kualitatif, dengan mengacu pada peraturan perundangan yag ada maupun informasi yang tersedia di media cetak maupun daring (online).

\section{HASIL DAN PEMBAHASAN}

Kebijakan dan strategi nasional (jakstranas) keselamatan nuklir dan radiasi bidang sumber daya manusia sebenarnya bisa menjadi modal dasar dalam menyusun strategi nasional untuk pendidikan dan pelatihan di bidang proteksi dan keselamatan radiasi.

Sayangnya, jakstranas sama sekali tidak menyinggung peningkatan jumlah sumber daya manusia untuk kegiatan pengembangan dan penerapan bidang proteksi dan keselamatan radiasi. Dari empat strategi di bidang sumber daya manusia yang disusun, hanya strategi pertama yang memiliki rencana peningkatan kapasitas sumber daya manusia, namun hanya untuk sumber daya manusia di bidang pengawasan dan tenaga ahli di bidang kesehatan seperti dokter spesialis radiologi, fisikawan medik dan radiografer.

\section{Analisis Kebutuhan Diklat}

Seperti terlihat pada Tabel 1, sebanyak delapan instansi telah mendapat penunjukan oleh BAPETEN untuk menyelenggarakan diklat PPR. Sebagian besar diklat hanya untuk PPR Medik tingkat 2, karena barangkali kebutuhan pasar paling besar saat ini adalah untuk PPR Medik Tingkat 2 tersebut.

Namun demikian, sampai saat ini belum ada analisis ilmiah mengenai berapa jumlah sumber daya manusia yang dibutuhkan untuk kegiatan proteksi dan keselamatan radiasi. Dengan mengacu pada rekomendasi IAEA seperti telah disinggung sebelumnya, dapat dibahas beberapa parameter sebagai berikut: 
a. pengumpulan informasi mengenai fasilitas dan kegiatan yang ada:

Informasi dapat diperoleh dari jumlah izin pemanfaatan tenaga nuklir yang dikeluarkan oleh BAPETEN untuk kegiatan yang bersifat penerapan, dan jumlah kegiatan penelitian dan pengembangan terkait proteksi dan keselamatan radiasi yang dilakukan oleh instansi pemerintah atau barangkali juga oleh pihak swasta.

b. analisis persyaratan diklat yang ditentukan pada kerangka hukum dan peraturan, ditambah persyaratan khusus terkait dengan kualifikasi profesional:

Untuk kegiatan penerapan di lapangan, persyaratan diklat PPR yang ditetapkan oleh BAPETEN [8] sudah cukup memadai, walaupun masih banyak ruang penyempurnaan terutama untuk PPR Medik terkait pengakuan sebagai tenaga kesehatan oleh Kementerian Kesehatan, tingkat pendidikan, lama pelatihan dan kepastian karir melalui jabatan fungsional [9].

Selain PPR, beberapa personil lain yang terkait dengan pelaksanaan pemanfaatan tenaga nuklir juga bisa mendapat pendelegasian untuk melaksanakan tanggung jawab di bidang keselamatan radiasi [10]. Untuk ini perlu ditetapkan dengan jelas siapa saja yang masuk ke dalam kategori ini, disamping juga perlu disusun sistem pengakuan kualifikasi terhadap personil tersebut [5].

Untuk kegiatan penelitian dan pengembangan (litbang), sementara itu, perlu disusun persyaratan pendidikan yang komprehensif. Dalam kaitan terakhir perlu didorong partisipasi aktif dari organisasi profesi di bidang proteksi dan keselamatan radiasi untuk terlibat dalam penyusunan kurikulum pendidikan di bidang proteksi dan keselamatan radiasi ini.

c. evaluasi jumlah personil untuk setiap kategori profesional yang memerlukan diklat, termasuk pertimbangan mengenai kebutuhan akan pelatihan penyegaran:

Jumlah personil proteksi dan keselamatan radiasi untuk setiap kegiatan ketenaganukliran saat ini belum pernah dievaluasi. Untuk kegiatan penerapan di lapangan hanya kegiatan radiografi industri yang telah memiliki persyaratan personil PPR yang dibutuhkan, yaitu satu orang PPR untuk tiga peralatan radografi pada tiga lokasi yang berbeda, atau tiga peralatan radiografi pada satu kawasan [11].

Untuk menentukan jumlah personil PPR lapangan dan kegiatan litbang beberapa parameter tampaknya perlu dipertimbangkan, seperti tingkat risiko radiasi dari kegiatan, jumlah pekerja radiasi yang ada, dan lokasi kegiatan. Proyeksi kebutuhan jumlah personil yang diperlukan dapat disusun untuk setiap lima tahun sekali [5].

\section{Rancangan Program Diklat}

Rancangan program diklat dibuat dengan mempertimbangkan beberapa parameter sebagai berikut [5]:

a. Unsur program diklat nasional:

Program diklat nasional merupakan suatu kegiatan yang terjadwal yang diadakan dalam kerangka waktu tertentu untuk memenuhi kebutuhan diklat yang teridentifikasi. Karena itu, program harus memperhitungkan semua jenis diklat yang akan diberikan dengan menggunakan kapabilitas nasional, calon peserta, frekuensi dan lamanya penyelenggaraan.

Selain itu, penyelenggaraan diklat perlu pula dibarengi dengan kegiatan lain yang terkait, seperti kegiatan pelatihan untuk pelatih, pendirian peminatan proteksi dan keselamatan radiasi di perguruan tinggi dan pemerataan pusat-pusat pelatihan di seluruh wilayah Indonesia.

b. Kajian sumber daya dan kapabilitas nasional:

Dua pendekatan yang bisa digunakan untuk memperoleh informasi sumber daya dan kapabilitas adalah pendekatan institusi dan pendekatan kualifikasi. Pendekatan pertama dilakukan dengan mengumpulkan semua informasi mengenai instutusi yang menawarkan program pendidikan akademik terkait radiasi pengion, fisika medik, dan dokter spesialis radiologi diagnostik, radioterapi dan kedokteran nuklir, dan juga mengenai institusi yang memberikan pelatihan bagi PPR.

Di Indonesia, semua perguruan tinggi yang memiliki jurusan atau departemen fisika memberikan komponen radiasi pengion dalam kurikulumnya, namun hanya dua institusi yang memberikan topik radiasi pengion secara lebih mendalam, yaitu di Departemen Fisika FMIPA ITB dan Departemen Teknik Nuklir dan 
Teknik Fisika FT UGM. Sekolah kedinasan yang berada di lingkungan BATAN, yaitu Sekolah Tinggi Teknik Nuklir (STTN), juga memberikan pengetahuan tentang radiasi pengion secara lebih mendalam kepada mahasiswanya. Sementara itu, program pendidikan fisika medik dilaksanakan oleh beberapa perguruan tinggi seperti diberikan pada Tabel 2 [12], program pendidikan dokter spesialis radiologi dilakukan oleh Fakultas Kedokteran di tujuh perguruan tinggi negeri (UI, Unpad, Undip, UGM, UB, Unair dan Unhas), program pendidikan dokter spesialis radioterapi dilaksanakan oleh FKUI dan program pendidikan dokter spesialis kedokteran nuklir dilaksanakan oleh FK Unpad. Sedangkan penyelenggara pelatihan PPR seperti yang diberikan pada Tabel 1.

Tabel 2. Penyelenggara pendidikan akademik fisika medik di Indonesia.

\begin{tabular}{cl}
\hline No. & \multicolumn{1}{c}{ Nama } \\
\hline 1. & $\begin{array}{l}\text { KBI Fisika Medis dan Biofisika, } \\
\text { Departemen Fisika FMIPA UI }\end{array}$ \\
\hline 2. & $\begin{array}{l}\text { Divisi Riset Fisika Nuklir dan Biofisika, } \\
\text { FMIPA ITB }\end{array}$ \\
\hline 3. & $\begin{array}{l}\text { Peminatan Fisika Medis, Jurusan Fisika, } \\
\text { FSM Universitas Diponegoro }\end{array}$ \\
\hline 4. & $\begin{array}{l}\text { Peminatan Fisika Medis, Departemen } \\
\text { Fisika, FMIPA Universitas Brawijaya }\end{array}$ \\
\hline 5. & $\begin{array}{l}\text { Peminatan Fisika Medis, Departemen } \\
\text { Fisika, FMIPA Universitas Hasanuddin }\end{array}$ \\
\hline 6. & $\begin{array}{l}\text { Departemen Fisika, Fakultas Ilmu Alam, } \\
\text { Institut Teknologi 10 November }\end{array}$ \\
\hline 7. & $\begin{array}{l}\text { Program Studi Fisika, Fakultas Teknik dan } \\
\text { Sains, Universitas Nasional }\end{array}$ \\
\hline 8. & $\begin{array}{l}\text { Departemen Fisika, Fakultas Sains dan } \\
\text { Teknologi, Universitas Airlangga }\end{array}$ \\
\hline 9. & $\begin{array}{l}\text { Program Studi Fisika, Fakultas Sains dan } \\
\text { Matematika, Univ. Kristen Satya Wacana }\end{array}$ \\
\hline 10. & $\begin{array}{l}\text { Departemen Teknik Nuklir dan Teknik } \\
\text { Fisika, Fakultas Teknik, Univ. Gajah Mada }\end{array}$ \\
\hline
\end{tabular}

Pendekatan kedua, pendekatan kualifikasi, memerlukan identifikasi mengenai kualifikasi primer dari pekerja, dan komponen proteksi dan keselamatan radiasi dari program pendidikan yang memberikan kualifikasi primer tersebut. Dari kedua pendekatan kemudian dapat dilihat kelebihan atau kekurangan topik mata ajar yang dapat disesuaikan dengan kebutuhan program.

c. Kecocokan kebutuhan dengan sumber daya dan kapabilitas yang ada:
Pada parameter ini dilakukan pencocokan antara kebutuhan yang telah diidentifikasi dengan kapabilitas nasional diklat secara nasional yang ada. Proses pencocokan akan dapat mengetahui kebutuhan diklat yang dapat dipenuhi oleh sumber daya dan kapabilitas yang ada, dan dan juga kebutuhan akan pembangunan kapasitas di dalam negeri dengan bantuan sumber daya dari negara lain.

Setelah ketiga pertimbangan di atas telah selesai dilakukan maka akan terlihat apa yang perlu dilakukan, kapan dan dimana. Informasi ini menjadi masukan untuk melakukan tahapan berikutnya, yaitu merumuskan rincian program yang memenuhi kebutuhan diklat dengan menyusun jadwal program kerja dalam suatu kerangka waktu tertentu dengan memanfaatkan sumber sumber daya yang ada.

\section{Pengembangan dan Penerapan Program Diklat}

Tahapan ketiga dalam menyusun strategi nasional ini adalah membuat program diklat nasional secara nyata. Dua komponen dalam tahapan ini adalah pengembangan alat dan mekanisme yang sesuai, dan penerapan aktual dari kegiatan pada program diklat nasional [5].

Fokus dari komponen pengembangan adalah memastikan bahwa konten dan format setiap pelatihan yang akan diberikan sesuai dengan kebutuhan. Untuk ini perlu dipenuhi beberapa kriteria sebagai berikut:

a. Kriteria untuk konten dan format, seperti jumlah calon peserta, tujuan pembelajaran, silabus, lama pelaksanaan, persyaratan penyelenggara diklat dan pengajar, dll.

b. Kriteria penyelenggara diklat, seperti harus mematuhi kriteria konten dan format, membuat sendiri bahan ajar, dan menentukan format dan standar penilaian kelulusan;

c. Prosedur ujian: jika yang lulus perlu mengikuti ujian lebih lanjut untuk memperoleh kualifikasi tertentu (seperti PPR), hasil ujian dapat digunakan sebagai umpan balik untuk mengevaluasi kefektifan diklat yang diselenggarakan.

Untuk komponen penerapan, hal penting adalah program diklat nasional harus mendapat prioritas tanpa mengorbankan diklat yang telah rutin dilaksanakan. Selain itu perlu pula diperhatikan bahwa jika kompetensi atau 
fasilitas yang diperlukan tidak tersedia secara nasional dan peserta harus pergi ke luar negeri, harus dipastikan bahwa konten dan lamanya program sesuai dengan kebutuhan nasional yang telah disusun. Hal lain yang terkait dengan penerapan adalah adanya pengakuan resmi bagi penyelenggara diklat, seperti dalam bentuk akreditasi, dan dilaksanakannya program pelatihan bagi pelatih untuk menjamin kesinambungan pelaksanaan program diklat nasional yang diselenggarakan.

\section{Evaluasi Program Diklat}

Evaluasi program diklat dilakukan untuk memantau keefektifannya agar diklat tersebut tetap dapat berlangsung walau ada perubahan kebutuhan di masa selanjutnya. Perubahan dapat disebabkan antara lain oleh adanya metode atau teknik baru, atau juga peraturan perundangan yang baru. Evaluasi dapat dilakukan dalam bentuk kaji diri atau kaji eksternal.

Secara teknis, evaluasi program dklat nasional dapat dilakukan secara berkelanjutan, atau jangka panjang. Evaluasi berkelanjutan dilakukan setiap kali satu tahapan berhasil diselesaikan, sementara evaluasi jangka panjang dilakukan setelah semua tahapan diselesaikan. Untuk mendapat tingkat kepercayaan yang tinggi, semua kegiatan dilakukan dalam kerangka sistem manajemen mutu yang sesuai.

\section{Penyusun Strategi Nasional}

Dengan terus meningkatnya aplikasi tenaga nuklir di Indonesia, penyusunan strategi nasional diklat di bidang proteksi dan keselamatan radiasi menjadi suatu keniscayaan. Semua pihak yang terkait dengan pemanfaatan tenaga nuklir memiliki kepentingan yang sama untuk hadirnya strategi nasional ini, dan juga memiliki hak yang sama untuk memulai wacana untuk menyusunnya.

Dari sisi pemerintah, Badan Tenaga Nuklir Nasional (BATAN) atau Badan Pengawas Tenaga Nuklir (BAPETEN) sebagai instansi yang memiliki tugas di bidang ketenaganukliran dapat mengawali upaya penyusunan strategi nasional ini. Di lain pihak, institusi universitas atau perguruan tinggi yang memiliki kepedulian terhadap pengembangan iptek ketenaganukliran secara umum dan bidang proteksi dan keselamatan radiasi secara khusus juga dapat diharapkan untuk dapat memulai tugas penyusunan strategi nasional ini. Namun apa pun juga, penyusunan strategi nasional diklat di bidang proteksi dan keselamatan radiasi ini harus melibatkkan semua pemangku kepentingannya hingga strategi nasional dapat tersusun dengan sebaikbaiknya dan memenuhi kebutuhan nasional yang makin lama makin mendesak untuk dilakukan.

\section{KESIMPULAN}

Berdasar uraian di atas, strategi nasional pendidikan dan pelatihan di bidang proteksi dan keselamatan radiasi merupakan kebutuhan yang tidak bisa dipungkiri telah sangat mendesak untuk dimiliki. Strategi nasional meliputi analisis kebutuhan diklat, rancangan program diklat nasional, pengembangan dan penerapan program diklat, dan evaluasi program diklat. Penyusunannya dapat dimulai oleh instansi pemerintah seperti BATAN atau BAPETEN, atau juga oleh universitas atau perguruan tinggi yang memiliki kepedulian terhadap pengembangan iptek ketenaganukliran secara umum dan bidang proteksi dan keselamatan radiasi secara khusus di Indonesia. Namun yang pasti penyusunan strategi nasional ini harus melibatkan semua pemangku kepentingan hingga dapat tersusun dengan baik dan memenuhi kebutuhan nasional dalam kaitannya dengan pengembangan iptek ketenaganukliran di Indonesia.

\section{DAFTAR PUSTAKA}

1. Badan Pengawas Tenaga Nuklir (28 Februari 2019). Jumlah data izin per provinsi. Available: https://balis.bapeten. go.id/portal/web/index.php/sites/ktun-perprovinsi

2. Peraturan Pemerintah Nomor 33 Tahun 2007 tentang Keselamatan Radiasi Pengion dan Keamanan Sumber Radioaktif.

3. Departemen Fisika Universitas Indonesia (30 April 2019). Tentang Fisika UI. Available: http://www.fisika.ui.ac.id/en/ about/about_fisika

4. Anonim. Peraturan Presiden RI Nomor 60 Tahun 2019 tentang Kebijakan dan Strategi Nasional Keselamatan Nuklir dan Radiasi. 
5. IAEA, A Methodology for Establishing a National Strategy for Education and Training in Radiation, Transport and Waste Safety. Safety Report Series No.93. IAEA, Vienna, 2018.

6. IAEA, Building Competence in Radiation Protection and the Safe Use of Radiation Sources. Safety Standards Series No. RSG-1.4. IAEA, Vienna, 2001.

7. IAEA (30 April 2019). Education and Training Appraisal (EduTA). Available: www-ns.iaea.org/appraisal/eduta.asp

8. Anonim. Peraturan Kepala BAPETEN Nomor 16 Tahun 2014 tentang Surat Izin Bekerja Petugas Tertentu Yang Bekerja di Instalasi Yang Memanfaatkan Sumber Radiasi Pengion.

9. E. Hiswara, "Penguatan Posisi dan Peran Petugas Proteksi Radiasi Dalam Pelayanan
Kesehatan," in Prosiding Seminar Nasional SDM Teknologi nuklir, SSTN BATAN, Yogyakarta, 2016, pp. 129-134. ISSN 1978-0176.

10. Anonim. Peraturan Kepala BAPETEN Nomor 4 Tahun 2013 tentang Proteksi dan Keselamatan Radiasi Dalam Pemanfaatan Tenaga Nuklir.

11. Anonim. Peraturan Kepala BAPETEN Nomor 8 Tahun 2014 tentang Perubahan Atas Peraturan Kepala Badan Pengawas Tenaga Nuklir Nomor 7 Tahun 2009 tentang Keselamatan Radiasi Dalam Penggunaan Peralatan Radiografi Industri.

12. Noname (30 April 2019). Anggota Aliansi Institusi Pendidikan Fisika Medis Indonesia. Available: https://www.aipfmi. org/anggota 